\title{
ARTÍCULOS MÚSICA
}




\title{
RESUMEN
}

Con el propósito de reflexionar acerca de la investigación sobre música en Valparaíso, este texto presenta dos secciones complementarias: una bibliografía comentada y un estado del arte. El diálogo entre ambas permite identificar ciertos "enclaves" de la música porteña: el cosmopolitismo, la asociatividad, la bohemia y la experimentación. Además, se muestran algunas tendencias en la investigación reciente, como su vinculación con la gestión patrimonial y la producción de relatos testimoniales basados en fuentes orales.

Palabras clave: Valparaíso, cosmopolitismo, asociatividad, bohemia, experimentación

\begin{abstract}
With the aim of reflecting about the state of music research in Valparaiso, this paper presents two sections, both of which complement each other: first, an annotated bibliography; and, second, a discussion on the state of the art. The dialogue between both sections allows to identify four key concepts concerning music in Valparaiso: cosmopolitanism, associativity, nightlife, and experimentation. In addition, some trends in recent research are discussed, such as the link between music research and heritage projects, as well as the production of testimonial narratives based on oral sources.
\end{abstract}

Keywords: Valparaíso, cosmopolitanism, associativity, bohemian, experimentation 
Músicas en Valparaíso: Bibliografía comentada y estado del arte

Music in Valparaiso: Annotated bibliography and state of the art Pp. 14 a 49

\title{
MÚSICAS EN VALPARAÍSO: BIBLIOGRAFÍA COMENTADA Y ESTADO DEL ARTE
}

\author{
MUSIC IN VALPARAISO: ANNOTATED BIBLIOGRAPHY AND STATE OF \\ THE ART \\ Dra. Laura Jordán González \\ Pontificia Universidad Católica de Valparaíso \\ Chile*
}

\section{Presentación}

Siendo una de las principales zonas de desarrollo urbano, un punto crucial de contacto cultural con el mundo, una de las provincias más densamente pobladas del territorio y un sector que se sitúa a una proximidad estratégica de la capital de Chile, no es difícil justificar la pertinencia de la pregunta por cuál es el estado de la investigación sobre las músicas en Valparaíso. De hecho, ante una primera impresión de escasez bibliográfica, tampoco es sorprendente constatar que una buena parte de las historias musicales del país se fundan en numerosos relatos sobre el Puerto y sus alrededores. Aquí se trata, no obstante, no tanto de comprender la importancia de las músicas regionales para la historia chilena, sino que sobre todo de detenerse a observar algunas de sus especificidades. Por ello, este texto se construye en dos secciones complementarias que buscan responder a una pregunta general sobre el estado de la investigación sobre músicas en Valparaíso. Primero, se ofrece una bibliografía comentada, si no exhaustiva al menos diversa, que integra monografías históricas y (etno) musicológicas, textos periodísticos, crónicas, ensayos, y algunas tesis de posgrado. Luego, se presenta una discusión bibliográfica que pone en relieve algunos de los enclaves principales del conocimiento escrito que ha circulado sobre la música porteña: el cosmopolitismo, la asociatividad, la bohemia y la experimentación. Finalmente, se ofrece un balance general de la bibliografía revisada, con un breve comentario

Correo electrónico laura.jordan@pucv.cl Artículo recibido el 12/08/2019 y aceptado por el comité editorial el $4 / 11 / 2019$ 
sobre los procesos actuales de patrimonialización que entrelazan la declaración de la ciudad como sitio patrimonial de la UNESCO y la instalación allí de la máxima institucionalidad cultural del Estado.

\section{Bibliografía comentada}

Alvarado, Boris y Nelson Niño eds. (2012). Nueve miradas a la música desde Valparaíso: serie de artículos académicos para un nuevo siglo. Valparaíso: Pontificia Universidad Católica de Valparaíso, Ediciones Universitarias de Valparaíso.

Este libro, que celebra los cuarenta años del Instituto de Música de la PUCV, compila trabajos escritos por sus académicos con una edición que pretende poner en valor la producción creativa que emerge desde esta institución. Se organiza en dos partes, una que compila seis capítulos de investigación y ensayo, y otra que agrupa tres capítulos en los que los compositores Boris Alvarado, Enrique Reyes y Daniel Díaz Soto reflexionan y entregan, respectivamente, una exégesis de sus propias obras musicales.

De la primera parte conviene destacar su heterogeneidad, pues no todos los textos abordan músicas producidas en Valparaíso, pero sí todos ellos se sitúan como lecturas producidas desde las instituciones de formación musical de la ciudad. Así, por ejemplo, Valeria Valle presenta un "aporte a la enseñanza de la polifonía" a partir de la observación y experiencia de la convergencia entre contrapunto y armonía dentro del IMUS; mientras que Pablo Palacios examina el proyecto de la agrupación Planeta Minimal, alojado en la Universidad de Valparaíso, para sopesar la incorporación de la guitarra eléctrica en la composición docta. Para ello recurre a una mirada histórica de la avant-garde europea, así como de las músicas populares masivas. Centra su análisis en un caso local, proponiendo una escucha a la producción fonográfica que el ensamble produjera en 2007. La semblanza al compositor y docente Hernán Ramírez y a la folclorista Margot Loyola, firmada por Silvia Herrera, se enmarca asimismo en el interés de reivindicar la labor de importantes figuras historia del IMUS y su antecesora Escuela de Música de la UCV.

Por otra parte, la producción de música escrita es puesta en relieve mediante el análisis que Rafael Díaz ofrece de obras de tres compositores locales en busca de lo que llama "mapuchismo borderline" ${ }^{\prime 1}$. También el capítulo de Nelson Niño aborda la 
composición escrita local, pero esta vez desde fuentes de prensa y más precisamente desde la revista Música. Allí observa cómo se organiza la actividad docta mediante círculos de aficionados (donde destaca el del croata Antonio Antoncich en Valparaíso) así como en espacios escolares como el Colegio Mackay. Entre las fuentes citadas se encuentran notas de autoría de Pablo Garrido y Jorge Valenzuela Llanos, importantes músicos e intelectuales ligados a Valparaíso por nacimiento y por residencia respectivamente. Un espacio es también asignado a la presencia del canto a lo pueta en la región de Valparaíso, a cargo del musicólogo Marcelo Fuentes, que organiza la información existente en la bibliografía existente, otorgándole encima una perspectiva local.

Aranda Riveros, Raúl, Carmen Carrillo Aguilera y Albert Casals Ibáñez. (2017). "Formación del profesorado de música en Chile: dos casos en la ciudad de Valparaíso". Debates I UNIRIO 18, pp. 248-278.

Este estudio se inscribe en la disciplina de educación musical y aborda como estudio de caso la formación profesional de profesores de música en dos instituciones universitarias porteñas: la Pontificia Universidad Católica de Valparaíso y Universidad de Playa Ancha. Se sitúa el caso en la historia de la educación musical en Chile y se expone como marco teórico... Los materiales analizados corresponden a documentos internos, autoevaluaciones y formularios de acreditación, proyectos educativos y modelos curriculares, y proyectos de mejora educativa. Se indaga en aspectos como el perfil de egreso, los elementos del currículo, las prácticas docentes y formación didáctica, admisión a la carrera y perfil de los académicos. Los resultados analizan integradamente los datos en función de tres ejes: los modelos formativos que subyacen en cada programa, sus procesos de formación práctica y la integración que ambas realizan entre la formación disciplinaria y la pedagógica.

Arce, Manuel. (2016). “La Nueva Canción Chilena en Valparaíso: Tiemponuevo y una nueva propuesta". En Nelson Niño Vásquez ed. Lecturas interdisciplinarias en torno a la música, Valparaíso: Pontificia Universidad Católica de Valparaíso, Ediciones Universitarias de Valparaíso, pp.193-211.

Artículo que indaga en el aporte específico de los integrantes de Tiemponuevo al movimiento de la Nueva Canción Chilena, contemplando tanto su relación con Valparaíso como sus características musicales para mostrar una diferencia estética y militante respecto de sus congéneres en Santiago. Se basa en fuentes bibliográficas secundarias, además de un análisis de fuentes sonoras.

Celis Fuentes, Andrés. (2018). Candilejas Bar. Cartografías culturales de una escena local en Valparaíso. Tesis para optar al grado de Magíster en Musicología 


\section{Latinoamericana. Santiago: Universidad Alberto Hurtado, Facultad de Filosofía y Humanidades.}

Esta tesis se adentra en el mundo singular de un local que funcionó por apenas unos años en uno de los centros neurálgicos de la bohemia de comienzos del siglo XXI en Valparaíso. Lo que el autor consigue con maestría es revelar el funcionamiento del Candilejas Bar como espacio de reunión y tránsito de músicos diversos que gestan una verdadera escena cultural. La investigación se apoya en la noción de escena cultural desarrollada por teóricos de los estudios culturales y de la musicología. El autor propone también una mirada que sitúa el caso específico de este local en la historia de la bohemia porteña y su relación con la música nocturna, pasando revista a lugares clásicos y a la embestida de la dictadura sobre las prácticas de diversión. Una reflexión importante, por último, conecta la escena del Candilejas Bar con la contingencia de la patrimonialización de Valparaíso.

Césped, Isabel. (2016). "Pedro Césari: compositor de héroes y gestas". En Nelson Niño Vásquez ed. Lecturas interdisciplinarias en torno a la música. Valparaíso: Pontificia Universidad Católica de Valparaíso, Ediciones Universitarias de Valparaíso, pp. 159-191.

Este artículo sintetiza un trabajo de investigación documental realizado en los Archivos de la Armada, concentrándose en las partituras pertenecientes a la banda de la institución y haciendo énfasis en un par de composiciones del italiano Pedro Césari dedicadas a las glorias navales y como comentarios de la realidad política contemporánea.

\section{Collipal Salas, Oscar. (2014). Chinganeando. Un enfoque antropológico de} la cueca chora porteña. Valparaíso: Ediciones Ideas.

A pesar de su título, este libro corresponde a un ensayo y no a una investigación elaborada desde la antropología. Se plantean en él ideas en torno a la identidad cultural, el componente "negroide" de la cueca, el mestizaje, el roto chileno, entre otros. Incluye una entrevista al cantor de cueca porteña Jorge Montiel.

Díaz, Rafael. (2016). “Viajan los lugares a las personas propicias: Valparaíso como el gettho de la música multirracial". En Nelson Niño Vásquez ed. Lecturas interdisciplinarias en torno a la música. Valparaíso: Pontificia Universidad Católica de Valparaíso, Ediciones Universitarias de Valparaíso, pp. 213-225.

Artículo que ofrece una mirada transversal a la actividad compositiva realizada en Valparaíso a comienzos del siglo XXI, proponiendo una interpretación de la estética porteña que enfatiza el elemento extranjero. Más que basarse en análisis musical, el texto corresponde a una apreciación general que intenta explorar un carácter unitario de la creación local a 
Músicas en Valparaíso: Bibliografía comentada y estado del arte Music in Valparaiso: Annotated bibliography and state of the art

partir de impresiones sobre un corpus selecto de obras de Boris Alvarado, Eduardo Cáceres, Félix Cárdenas, Daniel Díaz, Enrique Reyes y Valeria Valle.

Fuentes, Pepe (2014). A la pinta mía. Versos, viajes y memorias de la música chilena. Santiago: SCD Colección Nuestros Músicos.

Editado por el periodista especializado en música David Ponce, este libro reúne poesía del guitarrista Pepe Fuentes, fotografías de distintos músicos activos en escenas de música popular, y cápsulas históricas que organizan el resultado de una serie de entrevistas con músicos en torno a la historia de Pepe Fuentes y los géneros musicales en los que ha participado a lo largo de la segunda mitad del siglo XX, entre Santiago y Valparaíso.

González, Juan Pablo. (2013). “Vanguardia primitiva en el rock chileno de los años setenta: música, intelectuales y contracultura". En Pensar la música desde América Latina: Problemas e interrogantes. Santiago: Ediciones Alberto Hurtado. pp. 221-241.

Publicado primero como artículo de revista y luego como parte de este libro musicológico, este texto aborda una caracterización estética de Los Jaivas conectándola con la experimentación arquitectónica del proyecto Amereida de la UCV y la escena local porteña.

González, Juan Pablo. (2017). "Historia versus memoria”. En Des/encuentros de la música popular chilena 1970-1990. Santiago: Ediciones Alberto Hurtado, pp. 171-188.

En este capítulo de su libro de ensayos, el musicólogo reflexiona sobre el discurso fundacional de Los Jaivas en torno a la celebración de sus cincuenta años de trayectoria, proponiendo como hito alternativo al oficial la edición en 1972 del single de "Todos juntos", aduciendo que allí se cristaliza la propuesta estética que los haría reconocidos.

González, Patricio y Sebastián Redolés coords. (2019). Valparaíso, puerto de músicas: estudio preliminar para una historia de la música de Valparaíso. Valparaíso: Valparaíso Creativo.

Este documento publicado en formato digital a través de la plataforma de Valparaíso Creativo ofrece una mirada panorámica de las músicas en la ciudad, basándose en fuentes secundarias y proponiendo un relato cronológico desde los albores de la república hasta nuestros días. Se realiza un recuento de los principales hitos (visitas de músicos ilustres), así como la proliferación de espacios para el cultivo de la música, haciendo énfasis en los numerosos teatros que se instalan en la ciudad desde mediados del siglo XIX (remitiendo al influyente libro de Hernández 1928), las quintas de recreo (remitiendo a la serie de libros sobre cueca porteña aparecidos 
en los últimos años) y el rol fundamental de las instituciones de formación musical, destacando la labor de Margot Loyola y su Fondo desde la PUCV. También se hace hincapié en la importante labor de radioemisoras (destacando programas como "Música joven" en Radio Valentín Letelier o el programa "Dimensión latinoamericana" en Radio Valparaíso), festivales (como el Del Membrillo y el Valparatango) y carnavales (como el Mil tambores y los Culturales de Valparaíso). Se nombran numerosos músicos y agrupaciones de rock, pop, cueca, música antigua, música coral, fusión y tango, entre otros.

Guerra, Cristián. (2006). "La música en los inicios de los cultos cristianos no católicos en Chile: El caso de la Union Church (Iglesia Unión) de Valparaíso, 1845-1890". Revista Musical Chilena 206, pp. 49-83.

Este artículo musicológico indaga en la instalación del protestantismo en el Puerto, el rol del misionero norteamericano David Trumbull y de la Iglesia Unión de Valparaíso y, singularmente, las prácticas musicales que forman parte del culto. Se destaca el canto de salmos e himnos y la utilización de himnarios especialmente adquiridos que apuntan a una concepción calvinista del canto congregacional; a lo que se suma, aunque con menor énfasis, la utilización del armonio y más tarde la del órgano. Se expone asimismo la labor de la Escuela Dominical de Música, la influencia de Trumbull y otras figuras del protestantismo en la apertura de colegios en la provincia (entre los que se cuenta por ejemplo el Colegio MacKay), y la participación en distintas asociaciones. Se propone una tensión entre canto congregacional apegado a su función de adoración y el canto coral con connotación cultural que se instalaría desde la década de 1880 en adelante.

Guerrero, Claudio y Alekos Vuskovic. (2018). La música del Nuevo Cine Chileno. Santiago: Cuarto Propio.

Este libro coescrito por un especialista en música de cine y un historiador del arte aborda las bandas sonoras de una serie de películas producidas en Chile en la segunda mitad del siglo XX, muchas pertenecientes al llamado Nuevo Cine. Entre los capítulos monográficos se encuentran tres que atañen a la provincia: uno dedicado a la película A Valparaíso (Ivens 1964), otro al filme Valparaíso, mi amor (Francia 1969) y finalmente uno dedicado a Palomita Blanca (Ruiz 1973), cuya banda sonora fue compuesta por Los Jaivas. Combinando una investigación documental con análisis musical, estos capítulos sirven respectivamente para calibrar la imaginación sonora en torno al puerto, la popularidad de ciertos repertorios bohemios (notando en particularidad el rol estructurante de "La joya del Pacífico") y la convergencia del lenguaje del rock progresivo con ideas liberales de la juventud. 
Hernández, Roberto (1928). Los primeros teatros de Valparaíso y el desarrollo general de nuestros espectáculos públicos. Valparaíso: Imprenta San Rafael.

Este libro es sin duda una obra ineludible para una historia de la música de concierto, no solamente en la región sino que también para una comprensión de las circulaciones nacionales y sudamericanas. Aborda la historia de distintos teatros de la ciudad, deteniéndose en detalles de funciones, giras y compañías. Se basa en fuentes hemerográficas y crónicas. A su vez, se ha vuelto una fuente fundamental para la historia de las actividades de concierto en la ciudad, siendo utilizado también para historias de géneros específicos como la zamacueca.

Izquierdo, José Manuel. (2011). “Totaleindruck o impresión total: La Telésfora de Aquinas Ried como proyecto político, creación literario-musical, reflejo personal y encuentro con el otro". Revista Musical Chilena 215, pp. 5-22.

Artículo musicológico que se dedica a la historia singular de la que había sido considerada por Pereira Salas como el primer drama lírico compuesto en Chile. La Telésfora es explorada aquí en virtud de las condiciones de inmigración de su autor, considerando su visión de la cultura dejada y de la encontrada.

Jaimes Manosalva, Melisa Johana. (2015). "Partituras musicales como patrimonio documental Acercamiento al consumo musical en Valparaíso". F@ro Revista Teórica del Departamento de Ciencias de la Comunicación 21, pp. 26-35.

En este artículo se intenta una sistematización inicial de los datos básicos de las casas editoriales activas en Valparaíso desde la segunda mitad del siglo XIX hasta mediados del XX. Se ofrece una mirada panorámica y se proporcionan datos como las direcciones de los locales en los que funcionaron algunas de estas empresas.

Jil Riveros, Carlos. (2012). El resurgimiento de la cueca urbana en Valparaíso. Valparaíso: USM Ediciones.

Libro concebido como una historia personal de la agrupación Los Afuerinos, importante conjunto de cueca porteña, escrito por uno de sus integrantes.

Jordán, Laura. (2014). “La Nueva Canción en Valparaíso: la melancolía del Gitano y la ironía del Payo". En Eileen Karmy Bolton y Martín Farías Zúñiga comps. Palimpsestos sonoros. Reflexiones sobre la Nueva Canción Chilena, Santiago: Ceibo Ediciones, pp. 163-181.

Pensado como un ensayo con base documental en revistas de las décadas de 1960 a 1990, este capítulo propone una mirada del componente de canción 
urbana aportado por Gitano Rodríguez y Payo Grondona al movimiento de la Nueva Canción Chilena. Se analizan también un par de canciones.

Karmy, Eileen y Cristian Molina. (2018). "Músicos como trabajadores. Estudio de caso de la Sociedad Musical de Socorros Mutuos de Valparaíso (1893-1930)". Resonancias 42, pp. 53-78.

Este artículo es uno de los resultados del proyecto Memoria Musical de Valparaíso y de los estudios doctorales de una de las autoras. En él se exhiben algunas de las problemáticas de las condiciones laborales de los músicos en Valparaíso en el cambio de siglo XIX al XX, así como algunas estrategias de asociatividad a través de las cuales los músicos organizados buscaron mejorar su situación. Además de proporcionar datos sobre el desarrollo del oficio de la música en bandas y orquestas de diversa índole, el estudio contribuye a un conocimiento todavía incipiente de la historia laboral de los músicos chilenos.

Martínez, Andrea, Zamora, Elías y Yasna Rivera. (2014). Cueca en Valparaíso. La vida de un cultor porteño. Valparaíso: Ediciones Universitarias de Valparaíso.

Financiado por el Fondo Nacional de Desarrollo Cultural y las Artes, Región de Valparaíso 2013, este libro es el resultado de una investigación de corte testimonial liderada por la antropóloga Andrea Martínez y que indaga en la vida y actividad musical de Elías Zamora, reconocido baterista porteño. Bajo la forma de una biografía, se expone su trayecto en tres etapas principales: inicios en la música, participación en espacios bohemios y agrupaciones activas hasta el golpe de Estado de 1973 y finalmente una etapa de consolidación de nuevos escenarios. Todas las etapas recalcan sitios de sociabilidad cruciales para la provincia y sus localidades vecinas: rodeos, quintas de recreo, locales del Barrio Puerto y del Barrio Almendral, así como espacios familiares en cerros. Destaca allí la fundación de la Isla de la fantasía, como lugar e instancia de cultivo de músicas populares y, particularmente, de la cueca. Por último, el libro cierra con un capítulo dedicado a los talleres que Elías Zamora realizó en el centro cultural La Laguna en el Cerro Barón en 2013, uno de cueca y otro de confección de panderos. El libro incluye numerosas fotografías tomadas por Yasna Rivera, así como otras del archivo personal del músico. Se incluyen además algunos mapas de sectores de la ciudad que permiten observar la concentración de espacios para la música en distintos momentos de la historia. La mayoría de lo expuesto en este trabajo proviene de entrevistas en profundidad con Elías Zamora, pero se incluyen también algo de bibliografía sobre cueca.

Martínez, Andrea; Oteiza, Rodrigo y Lorena Huenchuñir. (2017). Historia de Lucy Briceño. La mujer en la música de la bohemia porteña. Valparaíso: Ediciones Universitarias de Valparaíso. 
Con una vocación de reivindicación patrimonial de la figura de Lucy Briceño, cantante de boleros, valses, cuecas y otros repertorios, este libro escrito en cuatro partes por un equipo interdisciplinario toma varias formas de escritura. Primero ofrece Rodrigo Oteiza una contextualización de la historia cultural porteña y de su bohemia. Luego se expone una biografía de la cultora, dando extensos espacios a la transcripción de sus testimonios que versan sobre su infancia, sus oficios y sus actividades musicales, incluyendo su importante experiencia como bailarina. En tercer lugar, Lorena Huenchuñir pone en relación las prácticas de Briceño con la presencia de mujeres en la música popular porteña en la segunda mitad del siglo XX y muy especialmente vinculadas a géneros criollos. Finalmente, Andrea Martínez propone una valoración desde una perspectiva que se dice "feminista" y que dialoga con investigaciones incipientes sobre la mujer en la música chilena.

Merino, Luis. (1982). "Música y sociedad en el Valparaíso decimonónico". Die Musikkulturen Lateinamerikas im 19. Jahrundert. Kassel: Gustav Bosse Verlag Regensburg, pp. 199-235.

Se trata de uno de los textos más exhaustivos que se han escrito desde la musicología para narrar la historia musical porteña del siglo XIX. Se basa en fuentes hemerográficas (Las Bellas Artes, La Colonie Française, El Mensajero del Teatro de la Victoria, El Mercurio, La Semana, Semanario Musical, The Valparaiso Review), y una extensa bibliografía que privilegia estudios históricos, relatos de viaje y crónicas de época. Lo que el autor propone es una periodización en dos etapas principales de la vida musical porteña: formación (1811-1844) y maduración (1844-1900). Se atiende a aspectos socio-económicos y a la infraestructura musical, pero los cambios sustanciales se observan en la música ejecutada públicamente, destacando el paso de compañías internacionales primero incipiente y luego de gran desarrollo. Elementos de continuidad son las prácticas de salón de músicas burguesas, mientras que las músicas "folklóricas" (haciendo énfasis en las chinganas) se observan en la primera mitad del siglo. Se destaca en la segunda mitad la proliferación de asociaciones y el desarrollo de música compuesta en la ciudad.

A pesar de ser un trabajo de harta exhaustividad en el manejo de fuentes y que ofrece un panorama detallado de la actividad de conciertos y algunas prácticas populares, presumo que su circulación en las últimas décadas no ha sido extensa, debido a su aparición en papel en Alemania hace casi cuarenta años, y que por lo tanto, las investigaciones posteriores no se han dedicado a construir un diálogo con su relato.

\section{Molina, Cristian y Eileen Karmy. (2012). Tango viajero. Orquestas típicas en Valparaíso (1950-1973). Santiago: Mago Editores.}

Esta monografía musicológica proporciona una mirada detenida al desarrollo del género tanguero a lo largo de dos décadas, reuniendo una diversidad de fuentes primarias (de archivos personales y del Archivo del 
Sindicato de Músicos de Valparaíso), notas de prensa local y una serie de fuentes orales construidas a partir de entrevistas con músicos claves. Además de entretejer una historia que enfatiza en la llegada del tango desde Buenos Aires a través de la gira de Carlos Gardel y José Razzano de los espectáculos que distintas orquestas (como la de Julio de Caro) realizaron desde entonces, este libro reflexiona sobre la instalación del tango como género relevante del Puerto en el contexto de la promoción del folklore como cultura nacional. Se da cuenta entonces de los debates y de las condiciones particulares que permiten su desarrollo singular: la importancia de la asociatividad, el doble oficio de los músicos y la circulación de personas que fomenta el intercambio cultural.

Niño, Nelson. (2016). “Louis Moreau Gottschalk en Valparaíso: Música y homenajes en tiempos de guerra". En Nelson Niño Vásquez ed. Lecturas interdisciplinarias en torno a la música. Valparaíso: Pontificia Universidad Católica de Valparaíso, Ediciones Universitarias de Valparaíso, pp. 137-158.

Buscando complementar la historia ya conocida acerca de la visita de Gottschalk a Valparaíso, este capítulo examina en detalle la prensa porteña (El Mercurio) para observar cómo se conecta la experiencia del bombardeo sufrido en 1866 en el Puerto con las actividades musicales de este pianista y compositor estadounidense. Se recrean detalles de los once recitales, los tres festivales y un gran concierto a beneficio que diera en Valparaíso hacia fines del mismo año. Se recalca no solamente la participación de músicos locales, sino que también el homenaje a la ciudad ofrecido por Gottschalk, observando la gestión de las actividades y su relación con personalidades de la época. Se destaca la composición de la Gran marcha solemne dedicada a Chile.

Oteiza, Rodrigo y Andrea Martínez. (2016). Manuel Jorquera. Pintura chilena: Retratos y escenas de la cueca porteña. Valparaíso: Ediciones Universitarias de Valparaíso.

Este libro es el único de la bibliografía examinada que corresponde a un estudio iconográfico de música porteña. En específico, se trata de una puesta en valor y análisis de la producción pictórica de Manuel Jorquera en torno a la cueca. El libro incluye un capítulo inicial que plantea preguntas y posicionamientos en torno a la identidad cultural, presentando el caso de la Colección La Cueca como un elemento de elaboración patrimonial que dialoga con las ideas de mestizaje y heteronomía identitaria. El segundo capítulo corresponde a una propuesta analítica que valora la Colección en el marco de la producción pictórica local, indagando en la influencia de algunos referentes como Gonzalo Ilabaca, Mario Marúa y Loro Coirón. El tercer capítulo ofrece un panorama de la cueca porteña, destacando prácticas, espacios y discursos, destacando el impacto de las ideas de Fernando González Marabolí a través de la bibliografía y de las ideas profesadas por músicos y autores diversos. Finalmente se expone una selección de láminas que retratan algunas de las obras principales de la 
Colección, incluyendo dibujos y pinturas. El libro incluye en sus capítulos centrales algunas fotografías y afiches que registran la actividad de la cueca porteña en las últimas décadas.

Padilla, Pablo y Daniel Muñoz. (2008). “Valparaíso y Santiago" y “El Puerto”. En Cueca brava. La fiesta sin fin del roto chileno. Santiago: Ril Editores, pp. 149-165 y 183-188.

Se trata dos breves capítulos dentro de este libro dirigido al gran público, coescrito por un periodista y un actor y músico. En el primero se posiciona a Valparaíso como "verdadero centro de la cueca urbana". Se nombran conjuntos relevantes de la zona, como Los Afuerinos, Las Lulú de Pancho Gancho, Los Sementales de Playa Ancha y Los Paleteados del Puerto. En el segundo ubican espacios importantes para la práctica cuequera a comienzos del siglo XXI: el Ascensor a la Luna, la Isla de la Fantasía y el Rincón de las guitarras.

Pincheira Albrecht, Rodrigo. (2017). Los elementos: voces y asedios al grupo Congreso. Hualpén, Chile: Ediciones Nuevos Territorios.

Más de la mitad de este libro periodístico está dedicado a contundentes entrevistas con diferentes músicos que han pasado por el grupo Congreso, oriundo de Quilpué, provincia de Valparaíso. El resto del libro se dedica a breves ensayos en torno a temas estéticos de la banda como la intertextualidad, la recurrencia de la mirada en canciones del grupo, la fusión de distintos lenguajes instrumentales y la referencia a la alteridad.

Planet, Gonzalo. (2013) "Los Jaivas. La vida mágica". Se oyen los pasos. La historia de los primeros años del rock en Chile. Del beat y la psicodelia al folk rock. Santiago: La Tienda Nacional, pp. 227-255.

Este capítulo presenta una narración de la historia de Los Jaivas, hilando una prosa periodística con fragmentos de entrevistas a Claudio Parra. Identifica espacios de ensayo (como la Boite chichón) y de presentaciones; describe repertorios y prácticas del grupo como High-Bass, señalando cómo se incorporan referentes vanguardistas del cine y la música docta, así como el impacto de un viaje para la emergencia de Los Jaivas con su carácter improvisatorio. Se aborda la recepción en Santiago y la confluencia con el cine de Raúl Ruiz, la creación con orquesta sinfónica y el contexto hippie en el que se acoge su proyecto creativo. Lo interesante de este capítulo es que presenta una narración que se vuelve extensiva en la comprensión de Los Jaivas como un grupo musical que progresa de ser un conjunto de covers a un emblema de la música experimental.

Ramírez Hernández, Jaime. (2016). La Bandalismo: Transfiguración e hibridación de prácticas tradicionales y modernas de bandas de bronce del Norte Grande en Valparaíso. Tesis para obtener el grado de Magíster en Musicología 


\title{
Latinoamericana. Santiago: Universidad Alberto Hurtado, Facultad de Filosofía y Humanidades.
}

\begin{abstract}
Esta tesis se centra en la historia y estética musical de la agrupación Bandalismo, que instala en Valparaíso una versión adaptada de la banda de bronce nortina (con especial influencia de la Fiesta de la Tirana) para incorporar aspectos propios de música popular, como el bajo eléctrico y la presencia del charango. Se indaga en el impacto performativo que la banda tiene en la promoción de espacios distintos a las peñas en las que se inician, promoviendo en cambio el tambo como instancia festiva y de mayor presencia dancística. La tesis elabora su observación recurriendo a la clásica polaridad tradición-modernidad, subrayando los aspectos progresivos de la Bandalismo. Se destaca también el impacto sobre la tradicional Festividad de San Pedro, la que lograrían potenciar con una propuesta musical renovada.
\end{abstract}

Rodríguez, Osvaldo. (2015). Cantores que reflexionan. Notas para una historia personal de la Nueva Canción Chilena. Santiago: Editorial Hueders.

Se trata de uno de los libros más célebres del cantautor Gitano Rodríguez, publicado originalmente en 1984. En él se compilan breves relatos de sus vivencias en Chile y Europa, anotaciones de entrevistas ajenas, entrevistas propias, letras de canciones y ensayos. En su variedad se esboza, como dice su título, una perspectiva propia de la historia de la Nueva Canción Chilena, de la que fue parte desde Valparaíso y desde el exilio. Notables son sus relatos sobre las peñas De Valparaíso y Del Mar, así como de distintas visitas de Violeta Parra por la provincia.

Ruiz Zamora, Agustín. (1995). “Hegemonía y marginalidad en la religiosidad popular chilena: los bailes ceremoniales de la región de Valparaíso y su relación con la Iglesia Católica". Revista Musical Chilena 184, pp.65-84.

Este artículo aborda desde el concepto de religiosidad popular las prácticas de bailes chinos y bailes danzantes en la Región de Valparaíso, con un énfasis en sectores rurales que exceden la provincia. Se propone la existencia de una tensión entre las prácticas populares de bailes chinos y las instituciones oficiales de la Iglesia Católica, la cual se explica mediante el análisis de las particularidades devocionales y rituales, destacando el rol del alférez, los sacrificios y el desarrollo de una música que no calza con los conceptos oficiales. En cambio, los bailes danzantes, inspirados por bailes nortinos, habrían tenido recientemente una acogida más fluida debido a su carácter más festivo y coreográfico.

Ruiz Zamora, Agustín. (2001). “Organilleros de Chile: de la marginalidad al patrimonio. Apuntes para la historia social del oficio". Resonancias 9, pp. 55-86. 
A partir de una etnografía que indaga en las prácticas de organilleros en Santiago y Valparaíso, este artículo etnomusicológico busca una primera aproximación a su historia y vigencia "insólita" en Chile. Se propone un relato de la importación de los primeros instrumentos hacia fines del siglo XIX, con un auge alrededor de 1930 y el comienzo de una decadencia treinta años más tarde con el deterioro de piezas de los instrumentos. El artículo anuncia la construcción de los primeros organillos fabricados en Chile a fines de los 1990. Aduciendo el especial interés organológico se ofrece una tipología emic de los organillos en uso a fines del siglo XX en ambas ciudades, según los siguientes criterios: "formato, cantidad de flautas, tipos de instrumentos, registros y timbres, aspectos morfológicos del mueble". Los usos públicos y los tipos de repertorio son también abordados, destacando la importancia de los títulos de las piezas más conocidas para nombrar y distinguir los instrumentos. La mayor parte del artículo se dedica a caracterizar el rol del organillero (junto con el organillero) describiendo su oficio. Se propone una revalorización de esta práctica que permita pasar de la marginalidad a la consideración patrimonial. Se incluye lista de organillos en servicio.

Schiaffino, Santiago Lorenzo. (2002). "Las tertulias, los clubes y la filarmónica, algunas expresiones de sociabilidad en Valparaíso. 1840-1930". Boletín de la Academia Chilena de la Historia 111, pp. 79-98.

Basándose en distintas fuentes hemerográficas (El Correo de Aviso, El Diario, El Pacífico, El Vigía de Valparaíso, El Mercurio de Valparaíso, La Mariposa, La Semana, La Semana Porteña, La Unión, Revista de Sud-América, Sucesos, Teatros y Actualidad, Zig-Zag) y dialogando con fuentes de la historiografía, este estudio propone una lectura de la sociedad porteña como una sociedad apática, aburrida, triste y falta de diversiones, todo ello relacionado con una caracterización de la ciudad como un centro industrioso concentrado exclusivamente en el trabajo. En dicho marco, las tertulias, frecuentes hacia la independencia, menguan hacia la segunda parte del siglo XIX. Simultáneamente se ven aparecer clubes de las colonias extranjeras y luego algunos clubes locales (como el de Bomberos y el de la Unión) así como la Sociedad Filarmónica que cumpliría una importante labor en la socialización de los "apáticos" porteños. Ya desde mediados del XIX se habrían promovido otras instancias de asociatividad como la Sociedad Armónica, la Sociedad Musical de Valparaíso y más tarde el Club Musical de Valparaíso. Instituciones similares a la Sociedad Filarmónica se registran hacia el cambio de siglo, integrando a distintos sectores de la sociedad: Filarmónica de la Unión de Obreros, Filarmónica Carlos Condell, Filarmónica Francisco Bilbao, Centro Filarmónico la Paz y Centro de Victoria Musical. En suma, dice el autor, las tertulias fueron progresivamente reemplazadas por estas organizaciones, que promovieron la sociabilidad musical en el contexto de una población que distintas fuentes señalan como aburrida y apática. 
Silva Vargas, Fernando. (2008). "Formas de sociabilidad en una urbe portuaria: Valparaíso 1850-1910". Boletín de la Academia Chilena de la Historia 117, pp. 81-159.

Este extenso artículo de investigación histórica aborda a lo largo de sesenta años las distintas instancias y propósitos que los porteños y extranjeros residentes en Valparaíso se dieron para llevar a cabo su vida cultural. Habla entonces del cultivo de las artes, pero también de los deportes, las vacaciones y las recreaciones. En cuanto a la música, consigue exponer en detalle algunas particularidades de la provincia en comparación con Santiago, notando por ejemplo la ausencia virtual de grandes bailes. Por su parte, el teatro es presentado como el gran espacio de sociabilidad, al que concurren preferentemente los chilenos. Además de dar cuenta de los espacios y tipos de evento, el autor aborda el asunto del calendario de festividades y prácticas culturales, lo que permite observar momentos del año en que fueron más recurrentes ciertas músicas. Como otra bibliografía que aborda el periodo, hace hincapié en la asociatividad, nombrando una variedad de filarmónicas, clubes y otras organizaciones dadas al cultivo de la música.

Urbina Alvial, Pamela. (2013). Los Jaivas: 50 años de historia. Santiago: Ediciones B.

Más que una biografía, este libro reúne materiales diversos en torno al trayecto de Los Jaivas, incluyendo una narración de sus inicios escolares en Viña del Mar hasta su aniversario de cinco décadas en 2013. Los primeros capítulos se construyen sobre fuentes orales (la lista integra más de treinta entrevistas con músicos, periodistas, políticos, cineastas, entre otros) y algunas referencias hemerográficas (Hoy, Humor, La Bicicleta, Novedades, Ramona, Rockaxis, Súper Musicales). Un capítulo especialmente relevante para la investigación musicológica se titula "La sonoridad de Los Jaivas" y consiste en un corto ensayo que indaga en la instrumentación y ritmos de Los Jaivas. Se analiza en un capítulo propio la producción discográfica en consideración del diseño de sus carátulas. Contiene además una sección de breves notas sobre influencia del grupo en el cine, la escultura, la arquitectura y la danza. Al final se incluye un anexo con entrevistas cortas y una serie de fotografías. 
Músicas en Valparaíso: Bibliografía comentada y estado del arte Music in Valparaiso: Annotated bibliography and state of the art

\title{
II. Enclaves de la música porteña
}

\author{
Querido puerto chileno \\ Fragante como el laurel \\ Con suh guitarrah de plata \\ Te vino a cantar Gardel. \\ (Roberto Parra) ${ }^{2}$
}

Cueca chora, tango, guitarras luminosas y pasajeros miles, imágenes típicas de un Valparaíso ajetreado y nocturno que los versos de Roberto Parra consiguen cristalizar con maestría. El cosmopolitismo y la bohemia son, en efecto, dos caras de una configuración urbana que se constituye de escenas bullentes en una historia que parece a ratos decadente y en otros momentos notablemente pujante. ¿Y la experimentación? Consecuencia de los primeros: así como la ciudad se abre al mundo y aloja en sus ciernes un hervidero de músicas mezcladas, la cultura porteña construye creativamente sus modos de participar de la modernización, de ahí la experimentación que aparece asociada a varias de las músicas del Puerto, o al menos así suelen rememorarse en numerosos escritos que la relatan. ¿Cómo elaborar un paisaje común de los sonidos de esta ciudad y de su provincia que parta de estos enclaves - la presencia extranjera, la noche y la experimentación - para dibujar su diversidad y sus historias múltiples?

En realidad, incluir un estado del arte sobre la música en Valparaíso dentro de un número especial sobre música regional no resulta sencillo. Y su dificultad se plantea, me parece, por dos razones principales. Por una parte, y como decía al principio, si bien una primera indagación en bibliografía acerca de la música porteña pueda arrojar una sensación de escasez, lo cierto es que las historias generales sobre música chilena suelen integrar numerosas alusiones a las prácticas de Valparaíso, como parte de un influjo "central" (centralista, tal vez) que se conecta casi naturalmente con las prácticas santiaguinas. Dicho de otro modo, el conocimiento sobre música en esta provincia se cuela en buena parte de las historias más conocidas sobre la música en Chile: las de Eugenio Pereira Salas ${ }^{3}$, Samuel Claro Valdés junto a Jorge Urrutia Blondel ${ }^{4}$, y las de Juan Pablo González junto a Claudio Rolle ${ }^{5}$ y Oscar Ohlsen ${ }^{6}$, por nombrar algunas de

Parra, Roberto. (2012). Roberto Parra. La vida que yo he pasado. Santiago: Pehuén, p. 46.

Pereira Salas, Eugenio. (1941). Los Orígenes del arte musical en Chile. Santiago: Universitaria; Pereira Salas, Eugenio. (1957). Historia de la música en Chile, 1850-1900. Santiago: Publicaciones de la Universidad de Chile.

4 Claro Valdés, Samuel y Jorge Urrutia Blondel. (1973). Historia de la música en Chile. Santiago: Editorial Orbe.

5 González, Juan Pablo y Rolle, Claudio. (2004). Historia social de la música popular en Chile (1890-1950). Santiago Ediciones UC.

6 González, Juan Pablo, Claudio Rolle y Oscar Ohlsen. (2009). Historia social de la música popular en Chile (1950-1970). Santiago Ediciones UC. 
ellas, o las de Pablo Garrido sobre la cueca ${ }^{7}$, Álvaro Menanteau sobre el jazz ${ }^{8}$ Fabio Salas sobre el rock ${ }^{9}$. También aparecen compositores vinculados al gran Valparaíso (por nacimiento o residencia) en el canon de obras fundamentales de la música docta elaborado por Juan Pablo González y Rafael Díaz, a la par de una gran mayoría de santiaguinos y un puñado de otros provincianos ${ }^{10}$. De ahí que la pregunta por su especificidad amerite, primero, una relectura de la bibliografía sobre música en el país en busca de sus menciones dispersas. En este texto, este objetivo es llevado a cabo de manera parcial, aunque sí procurando cierta mirada sistemática y de conjunto que permita hacerse una primera idea acerca del lugar prominente que Valparaíso es y ocupa en la historia musical de Chile.

Por otra parte, y como se mostró en detalle más arriba, las últimas décadas han producido un abundante número de publicaciones dedicadas a músicos avecindados permanente o pasajeramente en Valparaíso, en la forma de biografías o crónicas. La dificultad en la examinación de este material remite a cuestiones básicas de definición: ¿con qué criterio se puede considerar la pertenencia porteña de tal o cual músico? ¿basta con su acta de nacimiento o con su registro de residencia? ¿se inscribe siempre geográficamente la música en el espacio de sus creadores? Tomando en cuenta la proyección nacional y a veces internacional de los cultores y artistas, ¿qué implica pensar aquí una revisión regional de las prácticas musicales? ¿cómo hacer justicia a la proyección de algunas figuras fuera de este territorio, reconociéndoles al mismo tiempo su presencia e impacto local? De esta segunda interrogante se desprende otra más complicada y es que necesariamente el estado del arte que aquí se presenta se acota a estudios publicados que nombran a Valparaíso en sus enunciados, quedando irremediablemente fuera una serie de investigaciones que, se podría argumentar, también darían cuenta de las prácticas presentes en esta localidad aunque como parte de un universo mayor.

Además de las historias generales y las publicaciones monográficas recién comentadas, se incluyen también algunos estudios musicológicos e históricos que han abordado géneros, prácticas o escenas musicales importantes para la provincia de Valparaíso, sin que su intención haya sido siempre dar cuenta de una mirada específicamente local. No obstante, varios de ellos sirven para ir

Garrido, Pablo. (1943). Biografía de la cueca. Santiago: Ercilla; Garrido, Pablo. (1979). Historial de la cueca. Valparaíso: Ediciones Universitarias de Valparaíso.

8 Menanteau, Álvaro. (2003). Historia del jazz en Chile. Santiago: Ocho Libros Editores.

9 Salas Zúñiga, Fabio. (1998). El grito del amor: una actualizada historia temática del rock. Santiago: LOM Ediciones; Salas Zúñiga, Fabio. (2003). La primavera terrestre. Cartografías del rock chileno y la Nueva Canción Chilena. Santiago: Editorial Cuarto Propio.

10 Me refiero a Andrés Alcalde, Hernán Ramírez y Eduardo Cáceres activos en Valparaíso; Boris Alvarado, Carlos Botto y Alejandro Guarello nacidos en Viña del Mar; y a Tomás Lefever proveniente de Valparaíso. Díaz, Rafael y Juan Pablo González. (2011). Cantus firmus. Mito y narrativa de la música chilena de arte del siglo XX. Santiago: Amapola Editores. 
hilvanando una lectura de conjunto que procure atender con mayor ahínco precisamente aquellas prácticas que han ocupado a los investigadores según distintos propósitos. Es importante hacer notar, en ese sentido, que han aparecido recientemente algunos trabajos que buscan al menos parcialmente hacerse cargo del estado del arte de la música en Valparaíso, ya sea desde una mirada académica interdisciplinaria ${ }^{11} \mathrm{o}$ bien desde la política cultural patrimonial como parte de las acciones conducentes al reconocimiento de Valparaíso como ciudad musical ${ }^{12}$.

Teniendo en cuenta que estas publicaciones sugieren un interés vigente por acceder a una mirada panorámica acerca de las músicas de la provincia, a continuación se presenta un estado del arte que apunta a responder a una interrogante inicial y general: ¿qué se ha investigado y escrito sobre música en Valparaíso? ¿hay elementos comunes que permitan hablar de un conocimiento transversal sobre sus prácticas musicales?

Considerando las dificultades ya expuestas, se organiza el texto central en dos secciones. Primero, se sintetiza lo que algunas de las historias generales sobre música en Chile más difundidas han señalado acerca de Valparaíso, enfatizando lo que también algunas investigaciones específicas sobre la ciudad han reconocido como principal característica de la pujanza decimonónica: el cosmopolitismo de la sociedad porteña, la importante contribución de extranjeros a las prácticas musicales y el desarrollo progresivo de un comercio musical y de instituciones propias. Segundo, se revisan estudios específicos sobre prácticas musicales populares de la provincia durante el siglo XX poniendo en relieve la caracterización de la vida nocturna de Valparaíso y su etiqueta como ciudad bohemia, incluyendo aquí las publicaciones monográficas que abordan trayectorias de vidas musicales asociadas a la región y destacando algunos referentes de la experimentación musical en la provincia. Ambas partes se relacionan en gran medida con la construcción de una imagen del Puerto de Valparaíso como un sitio de apertura al mundo y de innovación.

\section{1) Extranjeros en Valparaíso: cosmopolitismo y asociatividad}

Pensada en muchas crónicas como una extensión de Santiago, la región de Valparaíso parece haber sido considerada en su música, a menudo, como un remedo de la capital o un lugar tan cercano que no ameritaba viajes para trabajos de campo ni interrogaciones provincialistas. En los clásicos de la historia musical chilena mencionados más arriba se comprueba esta tendencia,

11 Nelson Niño Vásquez ed. (2016). Lecturas interdisciplinarias en torno a la música, Valparaíso: Pontificia Universidad Católica de Valparaíso, Ediciones Universitarias de Valparaíso.

12 González, Patricio y Sebastián Redolés coords. (2019). Valparaíso, puerto de músicas: estudio preliminar para una historia de la música de Valparaíso. Valparaíso: Valparaíso Creativo. 
justificada por el rol de circulación del puerto: recepción y vitrina hacia el mundo. Muchas de las menciones a Valparaíso en las investigaciones publicadas se acotan a señalar la entrada de personas y objetos, sin detenerse necesariamente en la permanencia de sus prácticas y usos respectivos. El riesgo para esta interpretación sería esencializar la apertura del puerto y convertir la llegada y salida de personas en un fenómeno sobrevaluado para la historia musical. Sin ánimo de caer en tal reduccionismo, sí es importante, no obstante, poner en relieve la notoria participación de extranjeros en la vida musical republicana. Si la llegada de músicos en barco para permanecer por períodos variables en la ciudad es un hecho central para conocer acerca de las circulaciones (como bien está abordando José Manuel Izquierdo en su FONDECYT en curso) ${ }^{13}$, sí hay algunos casos de músicos que decidieron quedarse en los que se ha notado su particular contribución a la vida de conciertos, a la asociatividad musical local y a la presencia de instrumentos, etc. Un caso interesante es el de Henry Lanza, que habría sido traído en 1840 a Chile para tomar el cargo de maestro de capilla de la Catedral de Santiago, cargo que ocupó por apenas seis años. Según Samuel Claro y Jorge Urrutia Blondel este destacado barítono habría pasado los últimos años como artista lírico y bombero, falleciendo en Valparaíso en 1869. No aparece en su nota biográfica ${ }^{14}$, lamentablemente, cuándo habría regresado al Puerto y parece, más bien, que su vida se desarrolló en un permanente tránsito entre distintas localidades. Su herencia, no obstante, se percibe en la ejecución de conciertos y en la labor pedagógica de su hija, como nota Eugenio Pereira Salas $^{15}$. Este caso, como en muchos otros, ayuda a repensar la pertinencia de buscar -o no- una historia local entre las líneas de la narración nacional.

Si asumimos que la llegada de músicos y su instalación como pedagogos y gestores de actividades musicales fue relevante no solamente para la cultura local sino que también para configurar prácticas entrelazadas con escenas santiaguinas, es igualmente importante considerar el rol crucial que cumple efectivamente Valparaíso al facilitar los tránsitos. Así es como uno de los tópicos más recurrentes de la bibliografía es el del carácter cosmopolita de la ciudad Puerto, que se observa particularmente con el incremento de inmigrantes de distintas nacionalidades desde los albores de la República en adelante. No obstante, este influjo puede enlazarse naturalmente con la actividad portuaria que desde la época colonial permitía el ingreso de objetos musicales desde el extranjero, ya sea para ser comercializados, como también para uso personal. Según Alejandro Vera, los registros de la Real Aduana activa en Valparaíso desde 1774 permiten observar el tránsito de insumos para uso doméstico, específicamente de teclados y cuerdas para instrumentos. Se destaca allí la

3 Me refiero al proyecto FONDECYT 11170265 titulado “Recepción, circulación y canonización de la ópera en tres puertos del Pacífico sur (Guayaquil, Lima y Valparaíso) entre 1830 y 1860".

14 Claro Valdés, Samuel y Jorge Urrutia Blondel. (1973). Historia de la música..., p. 80.

15 Pereira Salas, Eugenio. (1957). Historia de la música..., p. 257. 
ruta hacia y desde el Callao, que gracias a la información disponible sobre la fabricación de los instrumentos en los registros aduaneros, permite documentar la importación de pianofortes y claves de fabricación limeña ${ }^{16}$. Algunos datos de similar naturaleza pero más tardíos habían sido incluidos por Eugenio Pereira Salas, señalando una lista de instrumentos ingresados y registrados en un manuscrito la Contaduría Mayor de la Aduana de Valparaíso entre 1817 y $1818^{17}$.

Pero no se trata solamente de trayectorias, sino que este cosmopolitismo daría cuenta de un impacto en el modo que tiene la sociedad porteña de relacionarse con los "otros". Durante el siglo XIX Valparaíso se convierte efectivamente en una ciudad de apariencia extranjera que le permite distinguirse de Santiago por las visibles "costumbres inglesas" que ostenta. Este es uno de los puntos comparativos de los que se sirve el historiador Fernando Silva para abordar las formas de sociabilidad en Valparaíso en la segunda mitad del siglo ${ }^{18}$. Sin duda el desarrollo de la actividad teatral es crucial para la llegada de compañías extranjeras, la difusión de repertorios de óperas, zarzuelas y otros géneros, pero sobre todo, dice Silva, para la instalación de espacios de encuentro entre los porteños. Un estudio pormenorizado de los teatros en Valparaíso fue publicado en 1928 por Roberto Hernández ${ }^{19}$, siendo hasta el día de hoy una de las fuentes más citadas. De ella se extraen importantes referencias a espacios como el Teatro de la Victoria, el Teatro Odeón, el Teatro Circo, el Teatro Colón; así como a organizaciones señeras como la Sociedad Filarmónica fundada en 1848.

En su capítulo "El imperio de la ópera italiana"20, el historiador Eugenio Pereira Salas caracteriza la participación de compañías extranjeras en la programación operática de los teatros de Valparaíso, basando buena parte de sus informaciones en el libro Hernández y otra parte importante en observaciones de viajeros publicadas en numerosas relaciones y crónicas, así como en revistas y periódicos locales. Por su parte, además de crónicas y obras literarias, el estudio de Fernando Silva examina prensa local. Si bien los libros de Pereira Salas ya aportan (a pesar de la cuestionada precisión de sus datos) una buena parte de la información que sigue repitiéndose en publicaciones posteriores, para el caso de Valparaíso la monografía de Luis Merino ofrece una mirada panorámica situada específicamente en el Puerto ${ }^{21}$, como se comentó más arriba.

16 Vera, Alejandro (en prensa). El dulce reato de la música. La vida musical en Santiago de Chile durante el período colonial. Santiago: Ediciones UC.

17 Pereira Salas, Eugenio. (1941). Los Orígenes del arte musical en Chile. Santiago: Universitaria, p. 72.

18 Silva Vargas, Fernando. (2008). "Formas de sociabilidad en una urbe portuaria: Valparaíso 1850-1910". Boletín de la Academia Chilena de la Historia 117, pp. 81-159.

19 Hernández, Roberto (1928). Los primeros teatros de Valparaíso y el desarrollo general de nuestros espectáculos públicos. Valparaíso: Imprenta San Rafael.

Pereira Salas, Eugenio. (1957). Historia de la música..., pp. 11-31.

21 Merino, Luis. (1982). “Música y sociedad en el Valparaíso decimonónico”. Die Musikkulturen Lateinamerikas im 19. Jahrundert. Kassel: Gustav Bosse Verlag Regensburg, pp. 199-235. 
El importante papel de los extranjeros avecindados en la ciudad se nota allí en la asociatividad, mediante la fundación y participación en clubes, filarmónicas y asociaciones varias, así como en las redes que permitieron la organización de recitales de visitantes en Valparaíso y Viña del Mar. En este respecto, el texto de Nelson Niño enfatiza cómo la mirada de un virtuoso internacional, como Gottschalk, puede observarse en su comprometida actividad musical en su paso por el Puerto en $1866^{22}$.

La llegada de músicos extranjeros a través de Valparaíso ha sido bien expuesta por Eugenio Pereira Salas en Historia de la música, dando pistas del funcionamiento de pivote, como entrada y enlace hacia, además de Santiago, otras ciudades ${ }^{23}$ como Copiapó y Concepción, más valdría la pena rescatar para este recuento no solamente el rol que el Puerto cumple al dejar entrar sino que también las estadías más o menos largas que los músicos realizan en la ciudad. Un caso interesante de comentar es el de la obra La Telésfora, del alemán Aquinas Ried, estrenada en 1847 al poco tiempo de su llegada a Valparaíso. Según José Manuel Izquierdo, más que el primer drama lírico compuesto en Chile, esta obra refleja el impacto del encuentro con el otro, desde la mirada específica de un músico integrado a la colonia alemana asentada en la ciudad Puerto. Examinando su libreto y relacionándolo con la música y filosofía romántica, Izquierdo logra mostrar que la pregunta por cuán chilena es esta obra rebota ante una creación que no estaba pensada desde el nacionalismo, sino que desde "la impresión de libertad que tiene un alemán cercano a la revolución republicana de 1848 en un país que él siente como esencialmente libre, pero que pronto se dará cuenta que no lo es" ${ }^{24}$. En este sentido, el caso específico de La Telésfora permitiría pensar en la presencia de una creación conectada con los ideales y ejercicios habituales contemporáneamente en Europa, solo que experienciados desde este lugar.

El músico italiano Pedro Césari a fines del XIX es un caso interesante, por cuanto no solamente se conoce gracias a Isabel Césped algo de su composición musical dedicada a Valparaíso y a la contingencia bélica nacional ${ }^{25}$, sino que también se ha documentado su participación en algunas de las primeras asociaciones gremiales de músicos en Chile, según el proyecto "Memoria Musical de Valparaíso" ${ }_{26}$ llevado a cabo por Eileen Karmy y Cristián Molina.

22 Niño, Nelson. (2016). "Louis Moreau Gottschalk en Valparaíso: Música y homenajes en tiempos de guerra". En Nelson Niño Vásquez ed. Lecturas interdisciplinarias en torno a la música. Valparaíso: Pontificia Universidad Católica de Valparaíso, Ediciones Universitarias de Valparaíso, pp. 137-158..

23 Pereira Salas, Eugenio. (1957). Historia de la música..., p. 36.

24 Izquierdo, José Manuel. (2011). “Totaleindruck o impresión total: La Telésfora de Aquinas Ried como proyecto político, creación literario-musical, reflejo personal y encuentro con el otro". Revista Musical Chilena 215, p. 18.

25 Césped, Isabel. (2016). “Pedro Césari: compositor de héroes y gestas”. En Nelson Niño Vásquez ed. Lecturas interdisciplinarias en torno a la música. Valparaíso: Pontificia Universidad Católica de Valparaíso, Ediciones Universitarias de Valparaíso, pp. 159-191.

26 Karmy, Eileen y Cristián Molina. (2017). Memoria Musical de Valparaíso. http://memoriamusicalvalpo.cl/ Consultado el 25 de octubre de 2019. 
Con un énfasis en el trabajo de archivo, estos investigadores han catastrado, digitalizado y analizado una cantidad importante de documentos pertenecientes a dos históricas asociaciones gremiales de músicos de la región: la Sociedad Musical de Socorros Mutuos de Valparaíso (1893-1930) y el Sindicato de Músicos Profesionales de Valparaíso. Los resultados de investigación se han presentado fundamentalmente a través de un sitio web con notas, crónicas y cápsulas, aunque también han publicado un artículo que sintetiza y pone en discusión el material con marcos teóricos acerca del trabajo musical y la asociatividad. Así, Karmy y Molina demuestran cómo a partir de un estudio de caso es posible dar cuenta de las condiciones laborales del gremio ${ }^{27}$. En ese entendido, por una parte interesa aquí recalcar la labor política que tuvo el italiano Pedro Césari dentro de la vida cultural porteña, pero también se vuelve importante considerar su caso y el de su mutual como antecedentes acerca de las condiciones de músicos en el país a fines del XIX. Por último, el caso de este músico también permite pensar en la circulación de materiales como un rasgo relevante de las prácticas porteñas, pues habría publicado en Madrid en 1891 una traducción del libro Historia de la música antigua que parece haber sido difundido también en Valparaíso.

Mientras que el caso de Aquinas Ried permite reflexionar acerca de la pertinencia de las categorías nacionales/locales como identidades atribuibles a los músicos y sus obras en distintos contextos, el de Pedro Césari es muestra de una inserción en la sociedad chilena en ámbitos que desbordan la pura creación musical, apuntando a la necesidad de conocer las historias integrales de músicos de oficio. Mirados en conjunto estos casos, como tantos otros, dan cuenta asimismo de que la apertura que Valparaíso ha implicado de Chile a otros territorios se ha expresado notablemente a través de la presencia de migrantes, tanto de músicos como de extranjeros de distintas ocupaciones. Más allá de las figuras de renombre musical, el aporte que estos últimos han realizado a diversas actividades musicales se ha ilustrado más específicamente en estudios que abordan la vida cultural de colonias o colectividades nacionales. Así, por ejemplo, Cristián Guerra ha mostrado cómo la instalación de norteamericanos protestantes en el Cerro Alegre y sus alrededores conllevó no solamente el ingreso de un órgano decimonónico (1880) que sigue estando en uso en la Iglesia Anglicana Saint Paul, sino que también la incorporación de prácticas musicales propias al rito que eran singulares y que, aunque se llevaban a cabo inicialmente con armonio, se caracterizaban por ser un canto congregacional con fin devocional más que cultural ${ }^{28}$. Este caso, más que contribuir al conocimiento de música porteña ha permitido a Guerra concebir una historia de la música anglicana en el país desde el prisma cosmopolita que he venido

27 Karmy, Eileen y Cristian Molina. (2018). “Músicos como trabajadores. Estudio de caso de la Sociedad Musical de Socorros Mutuos de Valparaíso (1893-1930)". Resonancias 42, pp. 53-78.

28 Guerra, Cristián. (2006). "La música en los inicios de los cultos cristianos no católicos en Chile: El caso de la Union Church (Iglesia Unión) de Valparaíso, 1845-1890". Revista Musical Chilena 206, pp. 49-83. 
describiendo. Para este autor, de hecho, en Valparaíso se observa una tolerancia al protestantismo desconocida en el resto del país, esto en virtud de la fuerte presencia de inmigrantes en su proporción demográfica.

El cosmopolitismo vinculado a la actividad económica del Puerto se ha abordado también desde la historia por Santiago Lorenzo Schiaffino, quien ha indagado en una caracterización de la vida cultural de Valparaíso decimonónico ${ }^{29}$. Partiendo de la base de que la diversión no era bien considerada por las autoridades de la época, el historiador interpreta la cultura de la ciudad como una centrada en el trabajo y de carácter pujante en torno al comercio. Su visión de la vida cultural poco activa de los porteños se observa también en Silva aunque más matizada. Este agrega una mirada histórica profusa en detalles acerca de las principales instancias de sociabilidad (la mayoría de ellas musicales) en las que se involucraban tanto chilenos como extranjeros. Una de sus observaciones más interesantes es que ambos sectores de la población no necesariamente coincidían en los mismos teatros ni salones. Las colonias mostraron desde su instalación en el Puerto tendencia a agruparse entre connacionales y generar sus propias actividades musicales. Un ejemplo notable es el de los alemanes, quienes fundan el Club Alemán (1838), cuyo local servía para la reunión del Club de Canto, la Sociedad Santa Cecilia y el Club de Cítara ${ }^{30}$. Pero además de las instancias exclusivas de las colonias, Silva considera que los salones burgueses sirvieron explícitamente para propiciar algunos espacios de encuentro entre inmigrantes y chilenos que de otra manera no se frecuentaban.

Es bastante seguro sostener que la llegada de extranjeros propició distintos tipos de comercio musical, y de manera más específica, la instalación en Valparaíso de casas editoriales. Si bien es sabido que el desarrollo de la imprenta musical contó con Valparaíso como una de sus principales sedes ${ }^{31}$, junto a Santiago y, en menor medida, Concepción, no ha habido hasta el momento un estudio pormenorizado sobre las casas editoras de partituras. Una aproximación específica pero sucinta ha sido publicada por Johana Jaimes, intentando sistematizar los nombres y ubicaciones de varios comercios ${ }^{32}$. También podría ligarse con esta apertura del Puerto la importación de instrumentos, entre los que destaca el caso del ingreso de organillos en la primera parte del siglo XX. Como muestra Agustín Ruiz, en el marco de consumo y prácticas domésticas vinculadas a las partituras para aficionados, los organillos logran instalarse en la cultura porteña y permanecer contra viento y marea en uso hasta la actualidad.

29 Schiaffino, Santiago Lorenzo. (2002). “Las tertulias, los clubes y la filarmónica, algunas expresiones de sociabilidad en Valparaíso. 1840-1930". Boletín de la Academia Chilena de la Historia 111, pp. 79-98.

Silva Vargas, Fernando. (2008). "Formas de sociabilidad...", p. 111.

González, Juan Pablo y Rolle, Claudio. (2004). Historia social de la música..., pp. 101-114.

Jaimes Manosalva, Melisa Johana. (2015). “Partituras musicales como patrimonio documental Acercamiento al consumo musical en Valparaíso". F@ro Revista Teórica del Departamento de Ciencias de la Comunicación 21, pp. 26-35. 
Sería oportuno entonces que entender la incorporación de organillos como parte de un auge de la industria de partituras, las máquinas musicales y las prácticas domésticas ${ }^{33}$, ligadas a la modernización.

Si bien el cosmopolitismo aparece caracterizado fundamentalmente durante el XIX, para el siglo siguiente se observa aún esa cualidad del porteño "en el sentido de abierto al mundo y a las relaciones de negociación constante" ${ }^{\prime \prime}$, lo que enmarca también el desarrollo de la bohemia y la experimentación en músicas urbanas.

\section{2) Bohemias porteñas y experimentación}

La bibliografía es enfática en valorar la bullente actividad nocturna de Valparaíso hasta el golpe de Estado de 1973, lo que se aprecia en un gran número de boîtes, bares y "casas de niñas". Estos locales, combinados con quintas de recreo y espacios más convencionales de espectáculo musical como teatros y más adelante, las salas de concierto, posibilitan una imaginación de Valparaíso como ciudad sonora. Si durante el XIX, los salones y teatros habían servido para acoger bailes de máscaras y reuniones sociales, durante el XX esta variedad de locales permite la sociabilidad pública con música sonando, preferentemente durante las noches. En este marco es de especial importancia la contribución del músico e investigador porteño Pablo Garrido, quien es considerado como un pionero de la importación del jazz en Chile. Sus primeras excursiones en esta música orquestal y bailable se dieron en espacios como el Casino de Viña del Mar y en los Baños del Parque, importantes sitios de la bohemia ${ }^{35}$. Tanto su actividad como escritor y gestor como la profusa presencia de músicos extranjeros en Valparaíso aún a comienzos del siglo XX, debiera permitirnos hilar esta historia con la caracterización del cosmopolitismo. En esta línea es relevante retomar lo que Cristián Molina y Eileen Karmy han propuesto como estrategia de observación de la instalación del tango en Valparaíso, pues no se trata solamente de notar su llegada y presencia en espectáculos, ni su pura incorporación a los repertorios de orquestas locales, sino que también de notar cómo este género musical se entrelaza con prácticas propias de los músicos “de oficio", corrientes por entonces $^{36}$.

De las investigaciones recientes, es notoria la preocupación por generar

33 Ruiz Zamora, Agustín. (2001). “Organilleros de Chile: de la marginalidad al patrimonio. Apuntes para la historia social del oficio". Resonancias 9, p. 56.

34 Martínez, Andrea, Oteiza, Rodrigo y Lorena Huenchuñir. (2017). Historia de Lucy Briceño. La mujer en la música de la bohemia porteña. Valparaíso: Ediciones Universitarias de Valparaíso, p. 37.

35 Menanteau, Álvaro. (2003). Historia del jazz en Chile..., pp. 27-37.

36 Molina, Cristian y Eileen Karmy. (2012). Tango viajero. Orquestas típicas en Valparaíso (1950-1973). Santiago: Mago Editores. 
cartografías de las escenas musicales, como la elaborada por Andrés Celis para el sector de Calle Cumming ${ }^{37}$ o la confección de mapas de los barrios Puerto y el Almendral para retratar la ocupación del espacio en distintas investigaciones sobre la bohemia porteña ${ }^{38}$. También he colaborado en esa reflexión sobre el espacio en mi propia indagación sobre la relación de Gitano Rodríguez y payo Grondona con las geografías urbanas de Valparaíso ${ }^{39}$. Pero los rastros del vínculo entre bohemia y lugares se pueden encontrar también en textos dedicados a otras interrogantes.

En las últimas décadas se nota un interés de los investigadores por participar y dar cuenta de la reactivación de una escena de músicas populares criollas diversas, en la que se sitúa el llamado renacimiento de la cueca porteña con sus géneros aledaños. En algunos libros elaborados para el gran público, se combinan referencias porteñas y santiaguinas, como en el capítulo "Valparaíso y Santiago" del libro Cueca brava ${ }^{40}$, presentándose como una sola escena urbana de la zona central del país. También se pueden encontrar referencias a la cueca chora vinculada con el puerto en libros de mirada panorámica como el de Mario Rojas sobre la cueca brava ${ }^{41}$ y en la investigación doctoral en musicología de Christian Spencer que dedica un capítulo al famoso dúo Los Perlas, cuyo acordeonista era viñamarino ${ }^{42}$.

Las publicaciones monográficas sobre cueca porteña han provenido desde miradas antropológicas ${ }^{43}$ y periodísticas, siendo los resultados publicaciones en formato de biografías y crónicas basadas en fuentes orales. Ejemplos de ello son el libro Cueca en Valparaíso; La vida de un cultor porteño que construye una visión general de la cueca porteña a partir de la biografía del baterista Elías Zamora ${ }^{44}$. Este libro ofrece numerosos nombres de artistas, de locales, relatos de eventos específicos, además de una serie de fotografías y un par de mapas elaborados por los editores para ubicar los principales espacios de la bohemia porteña a lo largo del siglo XX. En la misma línea se encuentran las investigaciones sobre

37 Celis Fuentes, Andrés. (2018). Candilejas Bar. Cartografías culturales de una escena local en Valparaíso. Tesis para optar al grado de Magister en Musicología Latinoamericana. Santiago: Universidad Alberto Hurtado, Facultad de Filosofía y Humanidades.

38 Martínez, Andrea, Elías Zamora y Yasna Rivera. (2014). Cueca en Valparaíso. La vida de un cultor porteño. Valparaíso: Ediciones Universitarias de Valparaíso; Martínez, Andrea, Oteiza, Rodrigo y Lorena Huenchuñir. (2017). Historia de Lucy Briceño...

39 Jordán, Laura. (2014). "La Nueva Canción en Valparaíso: la melancolía del Gitano y la ironía del Payo". En Eileen Karmy Bolton y Martín Farías Zúñiga comps. Palimpsestos sonoros. Reflexiones sobre la Nueva Canción Chilena, Santiago: Ceibo Ediciones, pp. 163-181.

40 Padilla, Pablo y Daniel Muñoz. (2008). "Valparaíso y Santiago" y "El Puerto". En Cueca brava. La fiesta sin fin del roto chileno. Santiago: Ril Editores, pp. 149-165 y 183-188.

41 Rojas, Mario. (2012). El que sae, sae: crónica personal de la cueca brava. Santiago: Ocho libros.

42 Spencer, Christian. (2017). ¡Pego el grito en cualquier parte! Historia, tradición y performance de la cueca urbana en Santiago de Chile (1990-2010). Santiago: Ediciones Biblioteca Nacional.

43 Collipal Salas, Oscar. (2014). Chinganeando. Un enfoque antropológico de la cueca chora porteña. Valparaíso: Ediciones Ideas.

44 Martínez, Andrea, Elías Zamora y Yasna Rivera. (2014). Cueca en Valparaíso... 
la cantante Lucy Briceño que propone además una primera indagación sobre las mujeres en estas escenas populare ${ }^{45} \mathrm{y}$ sobre el pintor Manu Jorquera como parte integral de las nuevas prácticas de cueca en la ciudad de Valparaíso ${ }^{46}$.

Un caso similar es el de la edición de testimonios del guitarrista Pepe Fuentes A la pinta mía: versos, viajes y memorias de la música chilena, en el cual se describe a través de poesía popular y relatos basados en entrevistas múltiples, las características de una escena de música popular. Las memorias del guitarrista Pepe Fuentes, nacido en el sur pero instalado en Valparaíso desde mediados de la década de 1940 siendo apenas un adolescente, sirven para conocer el desarrollo de escenas de música popular que cruzan géneros (valses, cuecas, tonadas, boleros, tangos), espacios (radios, estudios de grabación, quintas de recreo, bares y restaurantes) y ciudades diversas, configurando un oficio de músico popular común a mediados del siglo $X X^{47}$. La profusa actividad realizada entre Valparaíso y Viña del Mar permite cartografiar locales específicos (Rancho Criollo, el Rincón de las Guitarras, El Nunca se Supo) así como conocer aspectos históricos de agrupaciones musicales importantes de la zona, como es por ejemplo el conjunto Fiesta Linda, liderado por Luis Bahamonde y Carmen Ruiz, por el que pasaron numerosos instrumentistas entre los que se cuentan algunos de renombre nacional como Humberto Campos $^{48}$.

Convendría agregar, acerca del conocimiento sobre la cueca, que se observa un énfasis en su calificación porteña en el contexto de lo que algunos llaman el "renacimiento" de la cueca urbana, a pesar de que desde las más antiguas referencias a la zamacueca y a la cueca "a secas", estas danzas han sido observadas en Valparaíso, si no antes, al menos simultáneamente que en Santiago ${ }^{49}$. ¿De dónde entonces la necesidad de diferenciar la cueca de la cueca porteña? Probablemente el énfasis en modos de ejecución vinculado con la actualización de las performances y de los discursos en torno a la identidad que requieren de diferenciaciones. En cuanto a la bibliografía, podría aventurarse también que la exposición separada de la cueca de Valparaíso dentro del influyente libro con las enseñanzas de Fernando González Marabolí haya impactado en la necesidad de reafirmar una diferencia de nombre ${ }^{50}$.

Así como estas bibliografías dan cuenta de los vínculos estrechos entre los músicos en Valparaíso y en Santiago (recordándonos los límites del ejercicio de

Martínez, Andrea, Rodrigo Oteiza y Lorena Huenchuñir. (2017). Historia de Lucy Briceño...

46 Oteiza, Rodrigo y Andrea Martínez. (2016). Manuel Jorquera. Pintura chilena: Retratos y escenas de la cueca porteña. Valparaíso: Ediciones Universitarias de Valparaíso.

47 Fuentes, Pepe (2014). A la pinta mía. Versos, viajes y memorias de la música chilena. Santiago: SCD Colección Nuestros Músicos.

48 Valdebenito, Mauricio. (2012). "Guitarra popular, urbana y chilena: 'Chile Lindo' y Humberto Campos”. Resonancias 30, pp. 49-71.

49 Garrido, Pablo. (1943). Biografía de la cueca...; Garrido, Pablo. (1979). Historial de la cueca...

50 Claro Valdés, Samuel, Carmen Peña y María Isabel Quevedo (1994). Chilena o cueca tradicional. Según las enseñanzas de don Fernando González Marabolí. Santiago: Ediciones UC. 
particularización que aquí se propone), algunas investigaciones han planteado justamente la interrogante por cómo se desarrolla la participación de músicos de la provincia de Valparaíso en el marco de movimientos musicales de alcance nacional. Así por ejemplo, procurando caracterizar la contribución "porteña" a la Nueva Canción Chilena, Manuel Arce se ha preguntado por los distintos grados de implicación política de los músicos, proponiendo que una mirada del caso regional podría poner en crisis la visión del movimiento como uno eminentemente militante ${ }^{51}$. En el caso de mi propio abordaje de las figuras de Osvaldo Rodríguez y Payo Grondona, he argumentado que sus obras, de marcado carácter citadino, han sufrido un proceso de folclorización de la canción urbana, complementario al proceso de urbanización de la canción folclórica con el que Rodrigo Torres había caracterizado a la Nueva Canción Chilena en general ${ }^{52}$.

En el caso del rock y sus subgéneros, sería extraño no reparar en la prominencia de dos bandas caracterizadas por sus exploraciones progresivas y de fusión: Los Jaivas y Congreso, la primera de Viña del Mar, la segunda de Quilpué. En las historias generales del rock que han pasado a ser clásicos, la cobertura de estas bandas incluye comentarios sobre su pertenencia territorial. Así, por ejemplo, Fabio Salas recalca que a comienzos de la década de los ochenta el rock chileno se mantiene ocupado con una vertiente de "rock con raíces" mientras en otros lugares se desarrollaba el heavy metal. En este fenómeno, Salas destaca precisamente la labor de Los Jaivas y de Congreso, agregando que a pesar del centralismo, "hay que conceder que lo más selecto y granado del Rock clásico chileno provino siempre de la V Región" ${ }^{53}$. En otro de sus libros más importantes, Salas ubica a ambas bandas como representantes del rock progresivo chileno y más adelante, junto a Los Blops, como las "tres agrupaciones que representan la cima de la música popular juvenil chilena" ${ }^{54}$.

En términos de sus abordajes específicos, es notorio el interés que Los Jaivas han suscitado en diversos periodistas, existiendo numerosos libros en homenaje a sus décadas de trayectoria, algunos de ellos autoimpulsados por la banda. Desde la musicología, vale la pena destacar dos textos breves dedicados a Los Jaivas por parte de Juan Pablo González. Uno de ellos se dedica a indagar en las múltiples fundaciones y existencias del grupo, lo que el autor relaciona con las funciones diversas que el grupo ha cumplido: banda de covers, conjunto bailable, grupo experimental ${ }^{55}$. El otro ensaya una lectura con perspectiva local que implica situar a Los Jaivas en el contexto de la experimentación artística

51 Arce, Manuel. (2016). "La Nueva Canción Chilena en Valparaíso: Tiemponuevo y una nueva propuesta". En Nelson Niño Vásquez ed. Lecturas interdisciplinarias en torno a la música, Valparaíso: Pontificia Universidad Católica de Valparaíso, Ediciones Universitarias de Valparaíso, pp.193-211.

52 Jordán, Laura. (2014). "La Nueva Canción en Valparaíso..."

53 Salas Zúñiga, Fabio. (2003). La primavera terrestre..., p. 161.

54 Salas Zúñiga, Fabio. (1998). El grito del amor..., p. 196. 
vivida en Valparaíso en la década del sesenta y más específicamente vincularlos con el proyecto Amereida de la Escuela de Arquitectura de la Universidad Católica de Valparaíso. González propone entender la estética de Los Jaivas como una "vanguardia primitivista"56, inspirada por el rock progresivo pero como vertiente indigenista; distante, sin embargo, de los indigenismos más difundidos en América Latina, como los del muralismo mexicano, la música nacionalista de concierto y el boom literario.

En su capítulo sobre Los Jaivas, el periodista Gonzalo Planet comparte algunos testimonios de Claudio Parra, pianista y uno de los fundadores, en los que relata cómo siendo estudiantes de liceo junto a sus hermanos y miembros del grupo tuvieron contacto con la bohemia porteña. En bares y cabarets a los que accedían clandestinamente, pudieron oír a músicos amigos tocar en orquestas y acceder a otros repertorios. "Valparaíso era una ventana al mundo, pasaban barcos de todas las nacionalidades. Entonces de repente llegaba un marino y alguien le compraba una guitarra. Los puertos tienen una vida especial, son muy diferentes a las otras ciudades" 57 . Correspondería detenerse aquí para comentar que no es solamente el origen viñamarino del conjunto lo que basta para entender estos estudios sobre Los Jaivas como parte del estado del arte acerca de la música en la provincia de Valparaíso, sino que el reconocimiento de prácticas y espacios específicos que configuran, al menos parcialmente, el universo sonoro que los funda. Lo cierto es que la pertenencia regional suele ser reconocida en los distintos escritos especializados, ubicándose junto a Congreso como referentes fundamentales de la música popular nacida en la zona.

Este último grupo de rock fusión, nacido en Quilpué, ha sido caracterizado por su experimentación, su difícil encasillamiento y su notorio anclaje regional. Así como el relato de Parra para Los Jaivas, en el reciente libro de Rodrigo Pincheira se encuentran los relatos de los porteños Jaime Atenas y Tilo González que remiten a sus andanzas bohemias, así como a las audiciones de Radio Valentín Letelier (singularmente el programa de Pirincho Cárcamo) para el acceso a distintos géneros musicales. Pincheira entonces se permite reflexionar sobre los imaginarios marítimos que inundan a Congreso, recalcando una tensión centro-periferia entre Valparaíso y Quilpué, siendo la primera "cosmopolita, citadina, bohemia, seductora y prohibida", mientras que la segunda, "pequeña,

55 González, Juan Pablo. (2017). "Historia versus memoria”. En Des/encuentros de la música popular chilena 1970-1990. Santiago: Ediciones Alberto Hurtado, pp. 171-188.

56 González, Juan Pablo. (2013). "Vanguardia primitiva en el rock chileno de los años setenta: música, intelectuales y contracultura". En Pensar la música desde América Latina: Problemas e interrogantes. Santiago: Ediciones Alberto Hurtado. pp. 221-241.

57 Claudio Parra citado en Planet, Gonzalo. (2013) "Los Jaivas. La vida mágica”. Se oyen los pasos. La historia de los primeros años del rock en Chile. Del beat y la psicodelia al folk rock. Santiago: La Tienda Nacional, p. 233. 
tradicional, conservadora, interior" ${ }^{\prime 28}$. Mientras que la oposición sirve aquí para reafirmar lo que vengo diciendo respecto de la presentación de Valparaíso según los enclaves dichos, no es menos cierto que en la práctica los músicos circulan por el gran Valparaíso sin que estas tensiones interfieran sus actividades.

La importancia de estos dos grupos -Los Jaivas y Congreso- no se debe buscar cotejar solo en la escritura académica y periodística, sino que también en el impacto estético sobre agrupaciones rockeras de Valparaíso y sus cercanías, o incluso en la construcción de una escena cultural porteña en la que confluyen radios, locales, instituciones formativas $\mathrm{y}$, por cierto, figuras emblemáticas de la música de la provincia ${ }^{59}$.

\section{Palabras de cierre}

A través de este texto he querido organizar una serie de lecturas en torno a las músicas de Valparaíso y compartir algunas impresiones en torno al estado del arte. Constatados varios obstáculos en la definición del objeto y habiendo escogido un corpus selecto de ítems bibliográficos para comentar y luego hacer dialogar, vale la pena sintetizar aquí algunos elementos centrales.

La bibliografía estudiada aborda una diversidad de géneros musicales que han sido desarrollados en distintos momentos dentro de la provincia. Uno de los más importantes durante el siglo XIX fue la ópera, al constituirse el Puerto como la entrada de repertorios y compañías. Paralelamente se han documentado músicas de salón y de chinganas, distintos bailes europeos y criollos, más o menos populares. De ellos destaca la zamacueca ${ }^{60}$ entre cuyas primeras fuentes se encuentran relatos de viajeros. Géneros vigentes durante el XX son muy diversos, pero podemos constatar que la investigación se ha concentrado en la cueca, el rock, la nueva canción, el tango, sin olvidar que muchos de sus músicos transitan de uno a otro, dando cuenta de escenas musicales que integran variados repertorios y espacios. Además, prácticas tradicionales como la realización de la Fiesta de San Pedro ${ }^{61}$, el cultivo del canto a lo pueta ${ }^{62}$, la

58 Pincheira Albrecht, Rodrigo. (2017). Los elementos: voces y asedios al grupo Congreso. Hualpén, Chile: Ediciones Nuevos Territorios, p. 169.

59 Celis Fuentes, Andrés. (2018). Candilejas Bar...

60 Garrido, Pablo. (1943). Biografía de la cueca...; Garrido, Pablo. (1979). Historial de la cueca...

61 Ramírez Hernández, Jaime. (2016). La Bandalismo: Transfiguración e hibridación de prácticas tradicionales y modernas de bandas de bronce del Norte Grande en Valparaíso. Tesis para obtener el grado de Magíster en Musicología Latinoamericana. Santiago: Universidad Alberto Hurtado, Facultad de Filosofía y Humanidades.

62 Ver el trabajo de Marcelo Fuentes en Alvarado, Boris y Nelson Niño eds. (2012). Nueve miradas a la música desde Valparaíso: serie de artículos académicos para un nuevo siglo. Valparaíso: Pontificia Universidad Católica de Valparaíso, Ediciones Universitarias de Valparaíso. 
vigencia de los bailes chinos ${ }^{63}$ y de la ejecución del organillo ${ }^{64}$ dan cuenta de usos de las músicas que exceden en muchos sentidos los términos principales en los que se ha construido este estado del arte.

Respecto a las preguntas de investigación que fundan los textos revisados, hay que señalar que muchos de los más recientes se interesan y participan de los procesos de patrimonialización, concentrándose en fuentes orales y proponiendo proyectos de escritura en coautoría con los cultores ${ }^{65}$. Antes de la instalación del Ministerio de las Artes, las Culturas y el Patrimonio, en incluso antes de la nominación de Valparaíso como patrimonio de la UNESCO, ya se encuentra en esta misma línea la investigación de Agustín Ruiz sobre los organillos. En ella se reivindica la fundación de la Corporación Cultural de Organilleros de Chile y se justifica la importancia de la conservación de estos instrumentos para el servicio del conocimiento patrimonial, por ejemplo para la reescritura de temas perdidos $^{66}$.

Otra tendencia en los textos revisados, es la revisión hemerográfica de periódicos y revistas sobre todo en estudios del siglo XIX, pero también en algunos del XX. Es notoria la ausencia generalizada de otros tipos de documentación de archivo, salvo el caso del proyecto Memoria Musical de Valparaíso que ha podido acceder a los acervos particulares del Sindicato de Músicos. También el estudio de Isabel Césped se basa en la examinación del Archivo de la Armada. Pero en general, esta ausencia dice relación con la falta de sistematización y puesta a disposición de los documentos institucionales, además de la consabida pérdida de registros que ha afectado a Valparaíso a lo largo de su historia de desastres. Una notable excepción es el Fondo Margot Loyola albergado por la Pontificia Universidad Católica de Valparaíso, en consideración de los años en que esta investigadora se desempeñó como docente en su Instituto de Música.

Habría que añadir que entre los temas pendientes queda una reflexión sobre la relevancia de la producción de escritos sobre música desde Valparaíso, esto es, la importante contribución de las Ediciones Universitarias de Valparaíso a la escritura académica sobre música en Chile. Asimismo, convendría desarrollar en otro sitio un análisis sobre la relación de los distintos espacios de formación musical con el desarrollo de escenas y lenguajes musicales de Valparaíso, recordando que más allá del cosmopolitismo y la bohemia, las prácticas sonoras

63 Ruiz Zamora, Agustín. (1995). “Hegemonía y marginalidad en la religiosidad popular chilena: los bailes ceremoniales de la región de Valparaíso y su relación con la Iglesia Católica". Revista Musical Chilena 184, pp.65-84.

64 Ruiz Zamora, Agustín. (2001). "Organilleros de Chile..."

65 Martínez, Andrea, Elías Zamora y Yasna Rivera. (2014). Cueca en Valparaíso...; Martínez, Andrea, Rodrigo Oteiza y Lorena Huenchuñir. (2017). Historia de Lucy Briceño...; Oteiza, Rodrigo y Andrea Martínez. (2016). Manuel Jorquera...

66 Ruiz Zamora, Agustín. (2001). “Organilleros de Chile...”, p. 75. 
de esta provincia se traviesan por las distintas instancias de sociabilidad vigentes al día de hoy. También quedan las interrogantes sobre otros géneros y prácticas musicales que no han sido abordados aquí como el hip hop, el punk, la salsa, la electrónica y el arte sonoro, solo por nombrar algunas de las expresiones que se dejan oír por los cerros y planicies y que complejizan el retrato que hasta aquí hemos podido construir. 


\section{BIBLIOGRAFÍA}

Alvarado, Boris y Nelson Niño eds. (2012). Nueve miradas a la música desde Valparaíso: serie de artículos académicos para un nuevo siglo. Valparaíso: Pontificia Universidad Católica de Valparaíso, Ediciones Universitarias de Valparaíso.

Aranda Riveros, Raúl, Carmen Carrillo Aguilera y Albert Casals Ibáñez (2017). "Formación del profesorado de música en Chile: dos casos en la ciudad de Valparaíso". Debates I UNIRIO 18, pp. 248-278.

Arce, Manuel (2016). “La Nueva Canción Chilena en Valparaíso: Tiemponuevo y una nueva propuesta". En Nelson Niño Vásquez ed. Lecturas interdisciplinarias en torno a la música, Valparaíso: Pontificia Universidad Católica de Valparaíso, Ediciones Universitarias de Valparaíso, pp.193-211.

Celis Fuentes, Andrés (2018). Candilejas Bar. Cartografías culturales de una escena local en Valparaíso. Tesis para optar al grado de Magíster en Musicología Latinoamericana. Santiago: Universidad Alberto Hurtado, Facultad de Filosofía y Humanidades.

Césped, Isabel (2016). "Pedro Césari: compositor de héroes y gestas". En Nelson Niño Vásquez ed. Lecturas interdisciplinarias en torno a la música. Valparaíso: Pontificia Universidad Católica de Valparaíso, Ediciones Universitarias de Valparaíso, pp. 159-191.

Claro Valdés, Samuel y Jorge Urrutia Blondel (1973). Historia de la música en Chile. Santiago: Editorial Orbe.

Claro Valdés, Samuel, Carmen Peña y María Isabel Quevedo (1994). Chilena o cueca tradicional. Según las enseñanzas de don Fernando González Marabolí. Santiago: Ediciones UC.

Collipal Salas, Oscar (2014). Chinganeando. Un enfoque antropológico de la cueca chora porteña. Valparaíso: Ediciones Ideas.

Díaz, Rafael y Juan Pablo González (2011). Cantus firmus. Mito y narrativa de la música chilena de arte del siglo XX. Santiago: Amapola Editores.

Díaz, Rafael (2013). La música originaria: Lecturas de Etnomusicología, Volumen 1. Santiago: Ediciones UC. 
Díaz, Rafael (2016). "Viajan los lugares a las personas propicias: Valparaíso como el gettho de la música multirracial". En Nelson Niño Vásquez ed. Lecturas interdisciplinarias en torno a la música. Valparaíso: Pontificia Universidad Católica de Valparaíso, Ediciones Universitarias de Valparaíso, pp. 213-225.

Fuentes, Pepe (2014). A la pinta mía. Versos, viajes y memorias de la música chilena. Santiago: SCD Colección Nuestros Músicos.

Garrido, Pablo (1943). Biografía de la cueca. Santiago: Ercilla.

Garrido, Pablo (1979). Historial de la cueca. Valparaíso: Ediciones Universitarias de Valparaíso.

González, Juan Pablo y Rolle, Claudio (2004). Historia social de la música popular en Chile (1890-1950). Santiago Ediciones UC.

González, Juan Pablo, Claudio Rolle y Oscar Ohlsen (2009). Historia social de la música popular en Chile (1950-1970). Santiago Ediciones UC.

González, Juan Pablo (2013). “Vanguardia primitiva en el rock chileno de los años setenta: música, intelectuales y contracultura". En Pensar la música desde América Latina: Problemas e interrogantes. Santiago: Ediciones Alberto Hurtado. pp. 221-241.

González, Juan Pablo (2017). "Historia versus memoria". En Des/encuentros de la música popular chilena 1970-1990. Santiago: Ediciones Alberto Hurtado, pp. 171-188.

González, Patricio y Sebastián Redolés coords. (2019). Valparaíso, puerto de músicas: estudio preliminar para una historia de la música de Valparaíso. Valparaíso: Valparaíso Creativo.

Guerra, Cristián (2006). “La música en los inicios de los cultos cristianos no católicos en Chile: El caso de la Union Church (Iglesia Unión) de Valparaíso, 1845-1890". Revista Musical Chilena 206, pp. 49-83.

Guerrero, Claudio y Alekos Vuskovic (2018). La música del Nuevo Cine Chileno. Santiago: Cuarto Propio.

Hernández, Roberto (1928). Los primeros teatros de Valparaíso y el desarrollo general de nuestros espectáculos públicos. Valparaíso: Imprenta San Rafael. 
Izquierdo, José Manuel (2011). “Totaleindruck o impresión total: La Telésfora de Aquinas Ried como proyecto político, creación literario-musical, reflejo personal y encuentro con el otro". Revista Musical Chilena 215, pp. 5-22.

Jaimes Manosalva, Melisa Johana (2015). "Partituras musicales como patrimonio documental Acercamiento al consumo musical en Valparaíso". F@ro Revista Teórica del Departamento de Ciencias de la Comunicación 21, pp. 2635.

Jil Riveros, Carlos (2012). El resurgimiento de la cueca urbana en Valparaíso. Valparaíso: USM Ediciones.

Jordán, Laura (2014). “La Nueva Canción en Valparaíso: la melancolía del Gitano y la ironía del Payo". En Eileen Karmy Bolton y Martín Farías Zúñiga comps. Palimpsestos sonoros. Reflexiones sobre la Nueva Canción Chilena, Santiago: Ceibo Ediciones, pp. 163-181.

Karmy, Eileen y Cristián Molina (2017). Memoria Musical de Valparaíso. http://memoriamusicalvalpo.cl/ Consultado el 25 de octubre de 2019.

Karmy, Eileen y Cristian Molina (2018). “Músicos como trabajadores. Estudio de caso de la Sociedad Musical de Socorros Mutuos de Valparaíso (18931930)". Resonancias 42, pp. 53-78.

Martínez, Andrea, Zamora, Elías y Yasna Rivera (2014). Cueca en Valparaíso. La vida de un cultor porteño. Valparaíso: Ediciones Universitarias de Valparaíso.

Martínez, Andrea; Oteiza, Rodrigo y Lorena Huenchuñir (2017). Historia de Lucy Briceño. La mujer en la música de la bohemia porteña. Valparaíso: Ediciones Universitarias de Valparaíso.

Menanteau, Álvaro (2003). Historia del jazz en Chile. Santiago: Ocho Libros Editores.

Merino, Luis (1982). "Música y sociedad en el Valparaíso decimonónico". Die Musikkulturen Lateinamerikas im 19. Jahrundert. Kassel: Gustav Bosse Verlag Regensburg, pp. 199-235.

Molina, Cristian y Eileen Karmy (2012). Tango viajero. Orquestas típicas en Valparaíso (1950-1973). Santiago: Mago Editores. 
Niño, Nelson (2016). “Louis Moreau Gottschalk en Valparaíso: Música y homenajes en tiempos de guerra". En Nelson Niño Vásquez ed. Lecturas interdisciplinarias en torno a la música. Valparaíso: Pontificia Universidad Católica de Valparaíso, Ediciones Universitarias de Valparaíso, pp. 137-158.

Oteiza, Rodrigo y Andrea Martínez (2016). Manuel Jorquera. Pintura chilena: Retratos y escenas de la cueca porteña. Valparaíso: Ediciones Universitarias de Valparaíso.

Padilla, Pablo y Daniel Muñoz (2008). “Valparaíso y Santiago” y “El Puerto". En Cueca brava. La fiesta sin fin del roto chileno. Santiago: Ril Editores, pp. 149-165 y 183-188.

Parra, Roberto (2012). Roberto Parra. La vida que yo he pasado. Santiago: Pehuén.

Pereira Salas, Eugenio (1941). Los Orígenes del arte musical en Chile. Santiago: Universitaria.

Pereira Salas, Eugenio (1957). Historia de la música en Chile, 1850-1900. Santiago: Publicaciones de la Universidad de Chile.

Pincheira Albrecht, Rodrigo (2017). Los elementos: voces y asedios al grupo Congreso. Hualpén, Chile: Ediciones Nuevos Territorios.

Planet, Gonzalo (2013) "Los Jaivas. La vida mágica". Se oyen los pasos. La historia de los primeros años del rock en Chile. Del beat y la psicodelia al folk rock. Santiago: La Tienda Nacional, pp. 227-255.

Ramírez Hernández, Jaime (2016). La Bandalismo: Transfiguración e hibridación de prácticas tradicionales y modernas de bandas de bronce del Norte Grande en Valparaíso. Tesis para obtener el grado de Magíster en Musicología Latinoamericana. Santiago: Universidad Alberto Hurtado, Facultad de Filosofía y Humanidades.

Rodríguez, Osvaldo (2015). Cantores que reflexionan. Notas para una historia personal de la Nueva Canción Chilena. Santiago: Editorial Hueders.

Rojas, Mario (2012). El que sae, sae: crónica personal de la cueca brava. Santiago: Ocho libros.

Ruiz Zamora, Agustín (1995). “Hegemonía y marginalidad en la religiosidad popular chilena: los bailes ceremoniales de la región de Valparaíso y su relación con la Iglesia Católica". Revista Musical Chilena 184, pp.65-84. 
Ruiz Zamora, Agustín (2001). “Organilleros de Chile: de la marginalidad al patrimonio. Apuntes para la historia social del oficio". Resonancias 9, pp. 55-86.

Salas Zúñiga, Fabio (1998). El grito del amor: una actualizada historia temática del rock. Santiago: LOM Ediciones.

Salas Zúñiga, Fabio. (2003). La primavera terrestre. Cartografías del rock chileno y la Nueva Canción Chilena. Santiago: Editorial Cuarto Propio.

Schiaffino, Santiago Lorenzo (2002). "Las tertulias, los clubes y la filarmónica, algunas expresiones de sociabilidad en Valparaíso. 1840-1930". Boletín de la Academia Chilena de la Historia 111, pp. 79-98.

Silva Vargas, Fernando (2008). "Formas de sociabilidad en una urbe portuaria: Valparaíso 1850-1910". Boletín de la Academia Chilena de la Historia 117, pp. 81-159.

Spencer, Christian (2017).jPego el grito en cualquier parte! Historia, tradición y performance de la cueca urbana en Santiago de Chile (1990-2010). Santiago: Ediciones Biblioteca Nacional.

Urbina Alvial, Pamela (2013). Los Jaivas: 50 años de historia. Santiago: Ediciones B.

Valdebenito, Mauricio (2012). “Guitarra popular, urbana y chilena: 'Chile Lindo' y Humberto Campos". Resonancias 30, pp. 49-71.

Vera, Alejandro (en prensa). El dulce reato de la música. La vida musical en Santiago de Chile durante el período colonial. Santiago: Ediciones UC. 